\title{
Article
}

\section{Evaluation of Serum Triglyceride and Total Cholesterol Status in Adolescent Smokers}

\author{
Afrin $L^{1}$, Sultana $R^{2}$, Ferdousi $S^{3}$, Ahmed $A^{4}$, Amin $M^{5}{ }^{5}$
}

Objectives: A cross sectional comparative study was performed to evaluate the changes of the serum lipid profile in apparently healthy adolescent male non smokers and smokers' subjects. Method: This study was carried out in the department of Physiology of Dhaka Medical College from January to December 2005. For this purpose, total 80 subjects with age range 12-19 years were selected, of whom 20 were non smokers (control) and 60 were smokers (experimental) who smoked for at least one year. Again smokers were grouped according to the number of cigarettes smoked per week, ( mild $<19$, moderate 20-59, heavy $>60$ ). Fasting serum Triglyceride and total Cholesterol levels of all subjects were measured. Data were compared between smokers and non smokers and between non smoker and mild moderate and heavy smokers and analyzed statistically by unpaired $\mathrm{t}$ test. Result: Mean \pm SD Triglyceride levels were $136.80 \mathrm{mg} / \mathrm{dl} \pm 42.18$ vs. $153.12 \mathrm{mg} / \mathrm{dl} \pm 26.66$ and Mean \pm SD Total Cholesterol levels were $165.20 \mathrm{mg} / \mathrm{dl} \pm 15.13 \mathrm{vs} 165.36 \mathrm{mg} / \mathrm{dl} \pm 10.12$ in non smokers and smokers respectively. there were no significant changes in the mean serum total cholesterol levels in adolescent smokers but the mean serum triglyceride level in smokers were significantly higher $(\mathrm{p}<0.01)$ than that of non smokers. hyper Triglyceridemia (TG level $>150 \mathrm{mg} / \mathrm{dl}$ ) were observed in $56 \%$ of smoker subjects whereas $36 \%$ in non smokers. The dose response effect of smoking was observed in serum triglyceride levels of smoker subgroups. Mean \pm SD TG levels in mild, moderate, heavy groups were $148.15 \mathrm{mg} / \mathrm{dl} \pm 21.32,152.8 \mathrm{mg} / \mathrm{dl} \pm 29.49,154.12 \mathrm{mg} / \mathrm{dl} \pm 23.75$ respectively. Conclusion: From the result of the present study it may be concluded that, cigarette smoking during adolescent period induces alteration in serum lipid levels in the direction of increased risk for coronary artery disease.

J Bangladesh Soc Physiol. 2006 Dec;(1):14-18. For author affiliations, see end of text.

\section{Introduction}

C igarette smoking is now acknowledged to be one of the leading causes of preventable morbidity and mortality and is one of the largest single preventable causes of ill health in the world ${ }^{1}$. Smoking is considered as an important factor in the stimulation of the development of atherosclerosis and cardiovascular diseases and associated with an average $70 \%$ increase in the risk of death from coronary artery disease ${ }^{2}$. Further more it is one of the main avoidable causes of death in the world ${ }^{3}$. Smoking is most likely to begin during adolescence and there is a common reported that children smoke their first cigarette while they were attending primary school ${ }^{4}$.

It has been observed that, the start of even modest cigarette smoking during adolescence and early adulthood adversely alters the serum lipid and lipoprotein levels. ${ }^{5-7}$ Smokers had higher risk for coronary artery disease compared to non smokers, partly attributed to some altered physiological factors including altered coagulation state damaged vascular wall and alteration in lipid and lipoprotein content ${ }^{2}$.

A slow progression of atherosclerosis that begins in childhood and culminates in a variety of 


\section{Article}

clinical diseases such as myocardial infarction, cerebrovascular accident and peripheral vascular disease in middle age or later ${ }^{6,8}$. There is evidence from experimental study that cigarette smoking is related to production of oxidized LDL which contributes to foam cell formation and subsequent development of atherosclerosis in smokers. Analysis of published data from investigations carried out to study the effect of smoking on lipid levels in adults showed significantly higher serum total cholesterol and triglyceride levels in smokers. Again the same analysis revealed Serum total cholesterol significantly decreased in younger smoker but increased in adult ${ }^{7}$. Dyslipidemia has been recognized as a major coronary risk factor which was defined as the presence of high serum total cholesterol level (TC>200mg/dl) and serum Triglyceride level (TG>150mg/dl) according to the USAATP-11 guidelines ${ }^{9-10}$. Statistical analysis of published data also showed that smoking was associated with significantly higher triglyceride and cholesterol ${ }^{2}$.

On further analysis several studies also have demonstrated dose response relationship between number of cigarettes smoked and change in serum lipid and lipoprotein level 6-7,18 Several investigators $6-7,18$ found normal serum cholesterol in adolescent cigarette smokers. In contrast lower level of serum total cholesterol in adolescent smokers was also reported 3,7,19. Again some study 6-7,18 reported higher level of triglyceride whereas others ${ }^{19}$ found no difference in triglyceride in adolescent smokers compared to non smokers. Despite the differences in view about the direction of changes in lipid levels in adolescent smoker, it is clear that smoking have an appreciable impact on lipid and lipoprotein levels in adolescent smokers if it continues to adult life can culminate in atherosclerotic cardiovascular disorder.

Cigarette smoking is a common problem in Bangladesh and also a major public health problem associated with cardiovascular and respiratory morbidity and mortality. The prevalence of cigarette smoking has reached its peak among high school students. Although many studies have been carried out examining lipid and lipoprotein profile in adult smokers but no such works have yet been carried out for studying adolescent male smokers in our country. So, the present study has been undertaken to investigate the effect of cigarette smoking on serum lipid and lipoprotein levels particularly serum total cholesterol (TC), serum triglyceride (TG), level in adolescent male smokers with a view to take rational approach for taking preventive measures.

\section{Methods}

This prospective observational study was carried out in the department of Physiology of Dhaka medical college from January to December 2005.

Total 80 apparently healthy male adolescents age ranged from 12-19 years were selected, of whom 20 were non smokers taken as control (Group A) and 60 were smokers selected as experimental (Group B). Again experimental subjects were subdivided in to Group $\mathrm{B}_{1} \mathrm{~B}_{2}, \mathrm{~B}_{2}$. Each group consisting 20 smokers according to number of cigarettes smoked per week. Those who smoked 1-19 cigarettes were included in $B_{1}, 20-59$ in $B_{2}$ and more than 60 in $\mathrm{B}_{3}$. All the control subjects had never smoked while the experimental subjects were considered as one who had smoked at least one or more cigarettes weekly for one year or more. The subjects were excluded for any endocrine, hepatic disease, diabetes mellitus, renal disease, cardiopulmonary diseases, history of drugs intake such as $\beta$-blocker, lipid lowering drugs, steroid therapy, obesity \& alcohol intake. Before inclusion in to the study all ethical considerations for the subjects were taken into account. The aim and benefit of the study were explained to each subject and they were encouraged for voluntary participation. A written informed consent was obtained from each subject. A through clinical examination was done and detail medical, family, personal socioeconomic drug and alcohol intake and dietary history and detail information about physical activity were recorded in prepared questionnaire. The subjects were advised for 12 


\section{Article}

hours overnight fasting. In the morning $5 \mathrm{ml}$ venous blood was drawn under proper aseptic precaution and serum was prepared by centrifugation and sent to the laboratory.

Serum Triglyceride and serum total cholesterol levels were determined in an auto analyzer HITACHI 902 in the laboratory of the clinical pathology of Bangladesh Medical College and Hospital.

Data were expressed as mean and standard deviation. Statistical analysis were done by unpaired "t" test to compare the groups and computerized in excel program.

\section{Results}

All subjects were male adolescents and students of secondary school and preliminary section of college. All of them belonged to middle socioeconomic class and reported similar type physical activity.

The anthropometric parameters of all study subjects are presented in Table-I. Mean $\pm \mathrm{SD}$ age , height and body mass index of two groups were 16.35 years \pm 1.98 vs. 16.81 years $\pm 1.75,1.6 \mathrm{~m}$ \pm 0.06 vs $1.57 \mathrm{~m} \pm 0.07,19.52 \mathrm{~kg} / \mathrm{sqm} \pm 1.62$ vs. $19.92 \mathrm{~kg} / \mathrm{sqm} \pm 2.58$ respectively. No statistically significant differences were observed between the groups in relation to age, height, BMI of the subjects. Therefore the biological and social factors were adjusted.

Table I : Mean \pm SD Age, Height and BMI of both groups $(\mathrm{n}=80)$

\begin{tabular}{lccc}
\hline Variable & $\begin{array}{c}\text { Group A } \\
(\mathrm{n}=20)\end{array}$ & $\begin{array}{c}\text { Group B } \\
(\mathrm{n}=60)\end{array}$ & $\begin{array}{c}\text { P } \\
\text { Value }\end{array}$ \\
\hline Age & $16.35 \pm$ & $16.81 \pm$ & \\
(years $)$ & 1.98 & 1.75 & $0.177^{\mathrm{ns}}$ \\
Height & $1.6 \pm$ & $1.57 \pm$ & \\
$(\mathrm{m})$ & 0.06 & 0.07 & $0.09^{\mathrm{ns}}$ \\
$\mathrm{BMI}$ & $19.52 \pm$ & $19.92 \pm$ & \\
$\left(\mathrm{Kg} / \mathrm{m}^{2}\right)$ & 1.62 & 2.58 & $0.217^{\mathrm{ns}}$ \\
\hline
\end{tabular}

Group A = Non smoker apparently healthy adolescent, Group $\mathrm{B}=$ Smoker apparently healthy adolescent
Fasting serum triglyceride and total cholesterol levels were examined and compared between smoker and non smoker groups. Mean $\pm \mathrm{SD}$ triglyceride and total cholesterol levels of both groups were $136.80 \mathrm{mg} / \mathrm{dl} \pm 42.18$ vs. $153.12 \mathrm{mg} /$ $\mathrm{dl} \pm 26.66,165.20 \mathrm{mg} / \mathrm{dl} \pm 15.13 \mathrm{vs} 165.36 \mathrm{mg} /$ $\mathrm{dl} \pm 10.12$ respectively. Mean serum triglyceride level was significantly higher $(\mathrm{p}<0.01)$ in smoker group than that of non smokers. But the men total cholesterol levels were almost similar and no significant difference was observed between them (Table-II).

Table II: Shows TG and total cholesterol levels

\begin{tabular}{lccc}
\hline Variable & $\begin{array}{c}\text { Group A } \\
(\mathrm{n}=20)\end{array}$ & $\begin{array}{c}\text { Group B } \\
(\mathrm{n}=60)\end{array}$ & $\begin{array}{c}\mathrm{P} \\
\text { Value }\end{array}$ \\
\hline $\begin{array}{l}\text { Serum total } \\
\text { cholesterol } \\
(\mathrm{mg} / \mathrm{dl})\end{array}$ & 165.20 & $165.36 \pm$ & $>0.5$ \\
$\mathrm{Mean} \pm \mathrm{SD}$ & & $10.12^{\mathrm{ns}}$ & \\
$\begin{array}{l}\text { Serum TG } \\
(\mathrm{mg} / \mathrm{dl})\end{array}$ & 136.80 & $153.12 \pm$ & $<0.01$ \\
Mean \pm SD & \pm 42.18 & $26.66^{* *}$ & \\
\hline
\end{tabular}

Hypertriglyceridemia was identified in 34 (52\%) among the 60 smoker adolescents, and in 7 (34\%) among 20 non smoker subjects as the cut off value $150 \mathrm{mg} / \mathrm{dl}$ for TG was used. The difference was statistically significant. On the other hand only 1(1.66\%) of smoker group had hypercholesterolemia on cut point for hypercholesterolemia was fixed at $200 \mathrm{mg} / \mathrm{dl}$. No one of the non smoker group had haypercholesterolemia (Figure 1).

Figure 1. Hypertriglyceridemia in \% subjects in smoker and non smoker group $(\mathrm{n}=80)$

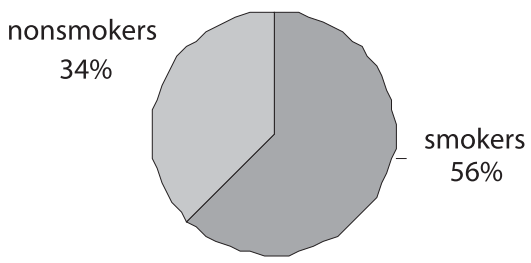

Dose response effect of mild, moderate, heavy smoking on lipid status in smokers was also analyzed and the results are presented in Figure 2.

J Bangladesh Soc Physiol. 2006 Dec;(1):14-18 


\section{Article}

Figure 2. Mean serum triglyceride levels in non smoker and 3 subgroups of smokers $(n=80)$

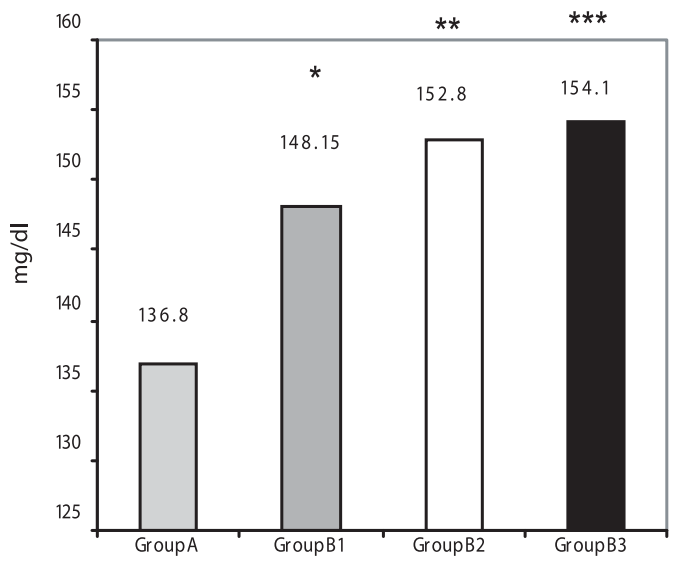

$*=\mathrm{p}<0.05 * *=\mathrm{p}<0.01 * * *=\mathrm{p}<0.001$, Group $\mathrm{A}=$ non smoker, Group $\mathrm{B}_{1}=$ smoker ( $<19$ cigerette/week), Group $\mathrm{B}_{2}=$ smoker (20-59 cigarettes/week), Group $\mathrm{B}_{3}=$ smoker $>60$ cigarettes/week)

Statistically no significant differences in relation to cholesterol were observed among $\mathrm{B}_{1}, \mathrm{~B}_{2}, \mathrm{~B}_{3}$ . But Progressively increased mean Triglyceride levels $(148.15 \mathrm{mg} / \mathrm{dl} \pm 21.32,152.8 \mathrm{mg} / \mathrm{dl} \pm$ $29.49,154.12 \mathrm{mg} / \mathrm{dl} \pm 23.75)$ among the $\mathrm{B}_{1}, \mathrm{~B}_{2}$, $\mathrm{B}_{3}$ were observed and the differences when compared with non smokers were statistically significant. $(\mathrm{p}<0.01, \mathrm{p}<0.01, \mathrm{p}<0.05)$.

\section{Discussion}

The present study was undertaken to evaluate the changes in the serum lipid profile in apparently healthy adolescent non smoker and smoker subjects to identify the possible high risk factor for developing atherosclerotic changes in early ages. Association of higher cholesterol and triglyceride levels with smoking has been investigated in a series of studies on both adolescents and adults. ${ }^{5-7,13,15,18}$ In this study, the mean serum total cholesterol and triglyceride levels in non smokers subjects were almost similar to those reported by other workers in different countries. ${ }^{20}$ Results of this study shows no significant changes in the mean serum total cholesterol levels in adolescent

J Bangladesh Soc Physiol. 2006 Dec;(1):14-18 smokers probably because of its opposing effects on different lipoprotein fractions as reported by different studies $6,18,21$ that smoking was not related to total cholesterol. But the mean serum triglyceride level was significantly higher in adolescent smokers compared to those of non smokers. These findings are also similar to those reported by other workers in different countries. $6,7,18$ The probable explanation for this change might be related to the effect of nicotine causing alteration in lipids in smokers. Nicotine stimulates sympathetic nerve activity leading to enhanced release of catecholamine from adrenal medulla which in turn causes increased rate of lipolysis. This effect results in raised plasma concentration of free fatty acid, triglyceride and increased hepatic production of endogenous VLDL. 2,6,13,16 In addition, Muscut et al. proposed the physiological change in appetite in smokers resulting in difference in dietary intake between smokers and non smokers is also responsible. ${ }^{13}$

Literature documents dose response relationship between degree of alteration in lipid profile and number of cigarettes smoked per day. In the present study a dose response effect in triglyceride level were observed among the smokers categorized according to the number of cigarettes smoked per week.. Though some study 8 differ but others ${ }^{13,15-16}$ reported similar findings. The effect of smoking on alteration of lipid status and its association with formation of atheromatous plaque is related to the frequency of cigarettes smoked per day. ${ }^{12,22}$ is well recognized. As suggested by other workers, the present observation also suggests that, the changes in serum lipid levels among smokers are proportional to the number of cigarette consumption per week. Again increased frequency of hypertriglyceridemia noted in the smoker adolescents in the present study indicating dyslipidemia similar to others ${ }^{8}$ also draws special attention at their increased risk to develop cardiovascular disorder.

It is evident from the findings of this study that, adolescent smoking may induce changes in the serum lipid levels towards an atherogenic 


\section{Article}

direction. The out come of this study therefore have emphasized the importance of controlling smoking behavior in adolescents to prevent the long term development of adult atherosclerotic cardiovascular diseases.

\section{Author Affiliations}

1. * Dr Lazina Afrin, Assistant Professor of Physiology, ZH Sikder Medical College, Dhaka, Bangladesh

2. Dr Rezina Sultana, Lecturer, Department of Physiology, Khaleda Zia Medical College, Dhaka, Bangladesh

3. Dr Sultana Ferdousi, Assistant Professor of Physiology, BSMMU, Dhaka, Bangladesh

4. Professor Abida Ahmed, Professor and Head of Physiology, Comilla Medical College, Comilla, Bangladesh

5. Professor Md Ruhul Amin, Professor and Head of Physiology, Dhaka Medical College, Dhaka Bangladesh

* for correspondence

\section{References}

1. WHO. Chronicle. 1983:37(3):86-90.

2. Craig WY, Palomaki GE, Haddow JE. Cigarette Smoking and Serum Lipid and Lipoprotein Concentration: An analysis of published data. BMJ 1989;298:784

3. Ghannem H., Harrabi I., Ben Abdelaziz A., Gaha R., Trabelsi L. Smoking habits and cardiovascular risk factors among adolescents in Sousse, Tunisia. Arch Public Health 2003; 61: 151-160.

4. Azevedo A, Machado AP, Baros H. Tobacco smoking among Portuguese High school students. Bulletin, WHO 1999; 77:6.

5. Glueck CJ, Heiss G, Morrison JA, Khoury P, Moore M. Alcohol intake, cigarette smoking and plasma lipids and lipoproteins in 12-19 year children. Circulation $1981 ; 64: 48-56$

6. Freedman DS, Srinivasan SR, Shear CL, Hunter SM, Croft JB, Webber LS, Berenson GS. Cigarette smoking initiation and longitudinal changes in serum lipids and lipoproteins in early adulthood: The Bogalusa Heart Study. Am J Epidemiol 1986;124(2):207-219.

7. Craig WY, Palomaki GE, Jojnson AM, Haddow JE. Cigarette smoking-associated changes in blood lipid and lipoprotein levels in the 8 to 19 year old age group: A meta analysis. American Academy of Pediatrics 1990;85(2):155-158.

8. Coelho VG; Caetano LF; Junior RDRL; Corderio JA; Souza DRS. Lipid profile and risk factors for cardiovascular diseases in medicine students. Arq. Bras. Cardiol 2005; 85: 1-13.

9. Rahman MA, Ali MA, Majumdar AAS, Haque KMHSS , Banoo H, Zaman MA Dyslipidemia and coronary Artery disease. Bangladesh Heart J 2001;16:(1):30-35.

10. Gupta R, Gupta VP, Sarma M, Bhatnagar S, Thanvi J, Sharma V, Singh AK, Gupta JB, Kaul V. Prevalence of coronary heart disease and risk factors in an urban Indian Population.: Jaipur Heart Watch-2. Indian heart J 2002;54:59-66.

11. Halfon ST., Green MS, Heiss G. Smoking status and lipid levels in adults of different ethnic origin: The Jerujalem Lipid Research clinic program. Int J Epidemiol 1984;13(2):177-183

12. Castelli WP. Cholesterol and lipids in the risk of coronary artery disease. The Framingham Heart study. Can J Cardiol 1988; 4A-5A

13. Muscat JE, Harris RE, Haley NJ, Wynder EL, Columbus. Cigarette Smoking and Plasma Cholesterol. Am Heart J 1991;121:141-147.

14. Fachini FS, Hollenbeck CB,Jeppesen J, Chen YDI, Reaven GDM. Insulin resistance and Cigerette smoking. The Lancet.1992;339:128-130.

15. Sirisali K, Poungvarin N, Kanluan T, Prabhant C. Serum Lipid, Lipoprotein-Cholesterol and Apolipoproteins A-I and B of Smoking and NonSmoking Males. J Med. Assoc Thai 1992;75:709-713.

16. Lee KS, Park CY, Meng KH, Bush A, Lee SH, Lee WC, Koo LW, Chung CK. The Association of Cigarette Smoking and Alcohol Consumption with Other Cardiovascular Risk Factors in Men from Seoul, Korea. Ann Epidemiol 1998;8:31-38.

17. Neki NS. Lipid profile in chronic smokers.-A clinical study. JIACM2002;3(1):51-4

18. Morrison JA, Kelly K, Mellies M, Groot ID, Khoury P, Gartside PS, Glueck CJ. Cigarette smoking, alcohol intake and oral contraceptives: relationships to lipids and lipoproteins in adolescent school children. Metabolism 1979;28(11):1166-1170.

19. Orchard TJ, Rodgers M, Hedley AJ, Mitchell JRA. Changes in blood lipid and blood pressure during adolescence, Brit Med J 1980;1563-1567

20. Bahar A, Sevgican U, Karademir F, Gocman I. Serum Cholesterol, Triglycride, VLDL-C, LDL-C and HDLC Levels in Healthy Children. Tohoku J. Exp. Med. 2003; 201:75

21. HigginsMW, Kjelberg M. Characteristics of smokers and non smokers in Tecumseh, Michigan. Am J Epidemiol 1967;86:60-77.

22. Oren A, Vos LE, Uiterwaal CSPM. Cardiovascular risk factors and increased carotid intima-media thickness in healthy young adults. Arch Intr Med 2003;163:178792.

J Bangladesh Soc Physiol. 2006 Dec;(1):14-18 